\title{
SEGUIR A LOS DIFUNTOS. Una etnografía multisituada de las prácticas funerarias transnacionales
}

\author{
Ariadna SOLÉ ARRARÀS \\ Universitat de Barcelona \\ ariadnasole@ub.edu
}

\begin{abstract}
FOLLOWING THE DECEASED. A multisited ethnography of transnational burial practices
\end{abstract}

Resumen: El presente artículo presenta una reflexión metodológica sobre el estudio de las prácticas funerarias en contexto trasnacional a las que dediqué mi tesis doctoral (2015) centrada en la repatriación de difuntos entre Catalunya y Kolda (Senegal). Es también el principal objeto del proyecto internacional MECMI con base en la UQAM (Canadà). La repatriación de difuntos es una práctica habitual entre distintos grupos migrantes y su estudio exige investigar en contextos múltiples, diseñar una etnografía que implica buscar constantemente un campo que se mueve, seguir a nuestro objeto de estudio por las cartografías que este mismo dibuja. La investigación de los ritos funerarios transnacionales exige usar elementos de las dos primeras formas o técnicas con las que la etnografía multisituada define sus objetos de estudio según George E. Marcus. El cuerpo difunto no es exactamente una cosa y su ambigüedad simbólica como persona y/o cosa ha sido un elemento de reflexión de la antropología de la muerte. Sin embargo, se trata de una forma de hacer etnografía que nos permite reflexionar como el ritual funerario transnacional es, en sí mismo, una forma de construir esta "comunidad transnacional".

Abstract: This article presents a methodological reflection on the study of funeral practices in a transnational context to which I dedicated my doctoral thesis (2015) focused on the repatriation of the deceased between Catalunya and Kolda, Senegal. It is also the main object of study of the international project MECMI (UQAM). The repatriation of the deceased is a common practice amongst different migrant groups and their study requires conducting research in multiple contexts, designing an ethnography that involves constantly looking for a field that keeps moving, following our object of study trough the cartographies that it itself draws. The investigation of transnational funeral rites requires the use of elements of the first two forms or techniques with which multisituated ethnography defines its objects according to George E. Marcus. The deceased body is not exactly a thing and its symbolic ambiguity as a person and / or thing has been an element of reflection on the anthropology of death. However, it is a way of doing ethnography that allows us to reflect on how the transnational funerary ritual is, in itself, a way of building this "transnational community".

Palabras clave: Ritual funerario. Transnacionalismo. Etnografía multisituada. Senegal. Islam Funerary ritual. Transnationalism. Multi-sited ethnography. Senegal. Islam 


\section{Introducción}

En un monográfico de la revista Global Networks dedicado a la cuestión, Katy Gardner y Ralph Grillo (2002) ponían sobre la mesa el concepto de "ritual transnacional". Proponían ir más allá del estudio de los envíos de remesas y otras actividades económicas que hasta la fecha habían protagonizado los trabajos sobre la dimensión transnacional de las prácticas de los colectivos migrantes, insistiendo en la necesidad de dedicar atención al estudio de las prácticas transnacionales dentro de las familias y en el ámbito doméstico. En este texto me propongo articular desde la antropología una reflexión metodológica sobre el estudio de las prácticas rituales en contexto transnacional. Concretamente de los rituales funerarios a los que dediqué mi tesis doctoral y que sigo trabajando actualmente. ${ }^{1}$

Mi tesis doctoral (Solé Arraràs, 2015) se centró concretamente en la repatriación de difuntos entre Catalunya y Kolda (Senegal). De hecho, muchos de los migrantes Senegaleses instalados en Catalunya proceden de esta región del sur de Senegal y en caso de muerte en Cataluña son en su mayoría repatriados a su país de origen. La región de Kolda o Fuladú se sitúa en el sur de Senegal. La mayor parte de habitantes de la región pertenecen a la etnia fulbe (peul en francés, fulani en la literatura anglo-sajona). La actual región administrativa de Kolda se corresponde a grandes rasgos con el territorio del antiguo reino del Fuladú nacido a mediados del siglo XIX de la revuelta de los fulbe dirigida por Alfa Molo contra el entonces dominio malinké del área. Su hijo, Moussa Molo, se convirtió al islam adoptando la vía Tijaniyya y animó a la población a seguir sus pasos. ${ }^{2}$ Aunque algunas áreas de la región no serán islamizadas hasta bien entrado el siglo XX, el islam es hoy un elemento clave de la identidad de los fulbe del Fuladú. Hoy en día Kolda es un área pobre respecto a otras regiones de Senegal con una elevada tasa de población rural (85\% de la población) y una economía basada en la agricultura y el ganado bovino. La población es esencialmente joven: más de la mitad de la población (58\%) tiene menos de 20 años. ${ }^{3}$ En esta coyuntura, migrar a Europa es una alternativa económica para muchas familias para lograr recursos para su sustento a través de las remesas de dinero enviadas por los migrantes, así como una forma de adquirir prestigio y poder.

Actualmente, España se ha convertido en uno de los principales destinos a los que se dirigen muchos migrantes senegaleses a pesar de la falta de lazos lingüísticos y la escasez de vínculos comerciales o históricos. En los años ochenta, fulbe y soninké constituirían un gru-

\footnotetext{
1 Esta investigación se produce en el marco del proyecto "Morts en contexte migratoire (MEMCI)" (20172020) dirigido por Lilyane Rachédi (UQAM) y financiado por la ANR-FRSCQ (Québec-Canada) y el CNRS (Francia). El equipo español del proyecto está integrado también por Jordi Moreras (URV) y Sol Tarrés (Universidad de Huelva).

2 La Tijaniyya es una de las cofradías más populares de Senegal, y la principal entre los fulbé. Fue creada en Marruecos a finales del siglo XVIII por Ahmed al-Tijani. En Senegal, la cofradía se propagó a manos del aristócrata El-Hadj Omar Seydou Tall durante el siglo XIX. En español, usamos la palabra "cofradía" para traducir la palabra árabe tariqa, literalmente "vía", puesto que se trata de una organización de inspiración sufí destinada a transmitir y difundir las enseñanzas de su fundador, una forma de acceder a Dios a través de determinados rituales, prácticas y conocimientos esotéricos (Popovic \& Veinstein, 1997: 11-31). Las turuq (pl.) tienen un gran peso en la sociedad senegalesa, no sólo por su organización religiosa sino en también en aspectos económicos y sociales. La tariqa tiene una organización piramidal liderada por un khalifa poseedor de baraka, sin embargo, la pertenencia a una u otra cofradía se basa en la relación personal que se establece entre el discípulo taalibe y el maestro seriñ o ceerno a través del wird que recibe individualmente, por la zyara (visita en que se honra al morabito) y por las intercesiones, oraciones, bendiciones que se le pueden pedir para obtener una ayuda, una curación, un trabajo etc. Aparte de esta relación personalizada, el discípulo pertenece habitualmente a una $d a$ hira, donde se agrupan musulmanes de la misma cofradía, y generalmente discípulos del mismo morabito y que organizan actividades como vigilias, oraciones, peregrinaciones etc.

3 Datos de 2011 procedentes de l'Agence Nationale de la Statistique et de la Démographie de la República de Senegal (http://www.ansd.sn/).
} 
po que instaló sobre todo en regiones agrícolas de la costa y del interior de Catalunya. Muchos de estos primeros migrantes tenían Francia como destino final. Por el endurecimiento de las leyes migratorias francesas a partir de 1973, Catalunya se convirtió en la última etapa de los que intentaban llegar al país vecino donde muchos encontraron oportunidades de trabajo, se establecieron e iniciaron las redes migratorias que ayudarían a otros senegaleses a instalarse (Sow \& Mercader, 2005). Sin embargo, la mayor parte de este movimiento migratorio es relativamente reciente ya que ha tenido lugar desde inicios de la primera década de los dos mil. La mayor parte de los que han intentado llegar a Europa en los últimos años son hombres jóvenes de zonas rurales y lo hacen de forma irregular. Residentes de la región de Kolda han llenado las noticias sobre piraguas interceptadas o hundidas y sobre miles de vidas perdidas en el mar (Naranjo, 2009).

A pesar de las particularidades de mi trabajo, hay que decir que la repatriación de difuntos es una práctica habitual entre distintos grupos migrantes y su estudio exige investigar en contextos múltiples, diseñar una etnografía que implica buscar constantemente un campo que se mueve. Centraré mi reflexión alrededor de las distintas formas de hacer etnografía multisituada que describe George E. Marcus (Marcus, 1998). La investigación de los ritos funerarios transnacionales exige usar elementos de las dos primeras formas o técnicas con las que la etnografía multisituada define sus objetos de estudio según Marcus: lo que él llama "follow the people" (seguir a las personas) y "follow the thing" (seguir una cosa). "Seguir a las personas" es la forma quizás más obvia y convencional de hacer etnografía multisituada en estudios que se desarrollan en contextos migratorios, como es el caso de mi tesis. Esta forma de construir una etnografía implica generalmente, centrar la búsqueda en un grupo bien delimitado que constituye una "comunidad transnacional" o "comunidad diaspórica". Ahora bien, que tal realidad exista es algo que sigue abierto a discusión.

\section{Hacia la construcción de una etnografía multisituada}

Tal y como sostienen los defensores de la perspectiva transnacional en el estudio de las migraciones ${ }^{4}$, los fenómenos que afectan a los colectivos migrantes se producen no solo en los países de instalación sino también en los países de origen con los que estos mantienen distintos tipos de relaciones (Gardner \& Grillo, 2002). Así, distintos aspectos de mi objeto de estudio, por su propia naturaleza, reclamaban que mi trabajo se realizara en escenarios muy diferentes y alejados entre sí y adquiriera la forma de una etnografía multisituada. El mismo G. E. Marcus (Marcus, 1998: 79) la define como aquella que "se mueve fuera de los lugares únicos y las situaciones locales de los diseños convencionales de investigación etnográfica para examinar la circulación de significados culturales, objetos e identidades en un espacio y tiempo difusos". Según Marcus, en el contexto actual, cualquier identidad cultural o actividad es construida por múltiples agentes y en diversos contextos o lugares y la etnografía debe concebirse para representar esta multiplicidad (Marcus, 1998: 52). Asimismo, debe ser capaz de captar el impacto de esta desterritorialización en las experiencias locales y el papel del sitio en la construcción de identidades.

La etnografía multisituada lleva asociados sus propios problemas metodológicos y mi tesis no fue una excepción. Inevitablemente, sus resultados son el producto de datos de diferente calidad e intensidad (Marcus, 1998: 84). Fragmentos de conocimiento cosidos en una trama por la misma narración etnográfica. Es una forma de hacer etnografía que desafía el tradicional modelo de la experiencia etnográfica malinowskiana alejada en el espacio y dilatada en el tiempo, pero que resulta de la necesidad de adaptarse al estudio de procesos de carácter transnacional propios del mundo actual y los fenómenos migratorios. Necesaria para poder captar la doble dimensión del emigrado-inmigrado sin la cual el estudio quedaría totalmente descabezado. Es por tanto, una etnografía que no se lleva a cabo en un lugar

4 Ver la definición pionera en: Glick Schiller, Basch, \& Blanc Szanton (1992). 
dado, es una etnografía móvil que sigue unos procesos, en este caso los rituales funerarios, a través de los espacios donde se desarrollan creando una cartografía propia del fenómeno trabajado.

Mi tesis comenzó a tomar forma en 2007 en el contexto de la realización de la memoria DEA que culminaba los estudios de doctorado en Antropología Social y Cultural en la Universidad de Barcelona. La memoria DEA titulada El último retorno. Islam, ritual y muerte entre los senegaleses de Lleida fue el embrión de este trabajo y se centró en las prácticas funerarias del colectivo senegalés de la ciudad de Lleida. Dejaba, por tanto, para la futura tesis doctoral el lado senegalés del fenómeno de la repatriación. Ya para la tesis la recogida de datos se realizó desde 2008 a 2015 de forma intermitente en Cataluña y en varias estancias de campo en Kolda.

Durante este tiempo, y a medida que la investigación avanzaba, los métodos de recogida de datos fueron evolucionando. En un inicio, en el momento de empezar a planificar un trabajo de campo, el primer problema que se nos plantea es acotar la unidad de estudio. Tenemos un objeto de estudio, preguntas más o menos dibujadas, pero para hacer trabajo de campo necesitamos precisamente eso, el campo. La accesibilidad, los condicionamientos prosaicos y prácticos del lugar donde acabamos realizando el trabajo forman parte del proceso de conocimiento y terminan por delimitar la unidad de estudio. Buscamos definir un conjunto de población, un grupo de personas sujetos de estudio. Asimismo, buscamos también un lugar o una institución que nos sirva de marco para la investigación, un ámbito físico donde encontrarlos y encontrarnos. Buena parte del esfuerzo del trabajo de campo consiste en el lento proceso de conseguir hablar con las personas adecuadas y concretar cómo se realizará el trabajo de campo.

Las necesidades de acotar la investigación me llevaron también a establecer unos límites que permitieran focalizar la investigación en unos espacios y un grupo de personas concretos. Escogí como escenario Kolda, las personas pertenecientes a la etnia fulbe, y los seguidores de la tariqa Tijaniyya para ilustrar los procesos investigados. Unos límites que, si bien son significativos para los informantes, fueron elegidos en un primer momento de una manera un poco casual. ¿Por qué estos y no otros? Fundamentalmente porque eran características comunes de los primeros casos de repatriaciones de difuntos con los que me encontré. Aun así, algunos argumentos científicos avalaban esta decisión, especialmente el hecho de que los fulbe procedentes de la región de Kolda son buena parte de los senegaleses instalados en Cataluña y la escasez de los trabajos que les han sido dedicados.

\section{Distintas caras de un mismo fenómeno}

El hilo que permitió unir ambos escenarios de mi investigación fueron los casos que pude seguir a través de observación y entrevistas a personas procedentes del Fuladú que murieron en Catalunya y cuyos cuerpos fueron trasladados a sus localidades de procedencia. Casos como el de un joven que enfermó y murió de una enfermedad grave o el de un niño que murió en un accidente. En ambos casos fueron repatriados a sus localidades de origen en la región de Kolda. Pero también el caso de un hombre que fue diagnosticado de una enfermedad terminal y siguiendo tratamiento paliativo pudo viajar gracias a la ayuda de sus familiares y vecinos para morir junto a su familia.

Se produce así un "ritual transnacional", un ritual que se lleva cabo en parte en Cataluña y en parte a Kolda en lo que Ruba Salih llama "división transnacional del espacio ritual" (Salih, 2002). Para el caso que nos ocupa, en Cataluña se llevan a cabo distintos aspectos importantes del ritual funerario, también si, como es habitual, el difunto es repatriado (baño ritual, oración para el difunto, prácticas de solidaridad comunitaria). Otros aspectos se repiten o se realizan en Kolda (la oración sobre el difunto, el funeral incluyendo el reparto de la sadaka, el entierro). 
El trabajo de campo en Cataluña me permitió estudiar, en primer lugar, el encaje del ritual funerario musulmán con las instituciones y sociedad catalanas. Se trata de un fenómeno que, en este sentido, no afecta solamente a los fulbe de Kolda sino al conjunto de las personas de religión musulmana que viven en Cataluña. La situación del entierro musulmán en Cataluña era un marco que había que investigar y se hizo en general, como una cuestión que afecta a todos los musulmanes. ${ }^{5}$ Consistió en un repaso a la situación del entierro islámico en Cataluña, así como en España y en Europa, y al marco legal catalán en materia de enterramientos. Además, se estudiaron las reivindicaciones por parte de colectivos musulmanes en Cataluña por la consecución de espacios para el entierro islámico, los espacios donde estos rituales pueden llevarse a cabo actualmente y el uso que se hace de este. Así, uno de los objetivos de la tesis era estudiar hasta qué punto la práctica de la repatriación es una respuesta a las dificultades para el entierro musulmán en Cataluña.

Un primer aspecto a destacar del ritual funerario islámico es el baño ritual del cuerpo. Se trata de un ritual de purificación que constituye una parte esencial de un funeral islámico. Lo llevan a cabo varias personas, generalmente del mismo sexo que el difunto y contando entre ellos, a menudo, con especialistas religiosos que conozcan con detalle la forma como se ha de realizar la limpieza según las prescripciones islámicas. Se trata de un ritual de purificación después del cual el cuerpo no debe ser manipulado de nuevo. El cadáver se cubre a continuación con una mortaja blanca. Cuando el cuerpo ha de ser trasladado, se realiza idealmente antes de situarlo en el féretro y después del embalsamamiento. Es habitual que en Catalunya los tanatorios cedan espacios para este fin e incluso se han construido instalaciones específicas (en el cementerio barcelonés de Montjuïc). A menudo, este ritual plantea dudas a los familiares en origen de forma que, si no se confía en que este haya sido correctamente realizado en Catalunya, puede volverse a realizar una vez en Senegal.

Los difuntos reciben también en Catalunya las oraciones debidas a los difuntos, una vez realizado el baño ritual puesto que se trata de otra de las obligaciones comunitarias en atención a la persona muerta. Se considera una oración meritoria, que incorpora elementos que difieren de las oraciones habituales y que también requieren de una orientación espacial significativa: se realiza todo el tiempo de pie, manteniendo la orientación hacia la alquibla y el cuerpo del difunto es situado frente del imán y de los que participan en la oración que son sólo hombres. Ocasionalmente, puede llevarse el difunto a la mezquita para realizar la oración, aunque también puede efectuarse en el domicilio, en el cementerio y habitualmente en el mismo tanatorio. En el domicilio o en la mezquita, suele realizarse una pequeña ceremonia de muestra de duelo en el que los familiares del difunto ofrecen comida a los asistentes. Aun así, las ceremonias que se realizan en Cataluña suelen ser sencillas, especialmente teniendo en cuenta las dimensiones fastuosas que alcanzan los enterramientos a Senegal. Además, para los difuntos en Cataluña o los familiares a Senegal se organizan sesiones de recitaciones del Corán e invocaciones a Dios $\left(d u^{\prime} \bar{a}^{\prime}\right)$ por el alma del difunto.

Cuando analizamos estos rituales transnacionales no podemos olvidar su dimensión económica puesto que suelen implicar siempre un coste elevado. Gardner y Grillo también insisten en que, si bien todos los rituales requieren la preparación de recursos humanos y materiales, las exigencias de los rituales transnacionales describen en términos de material (dinero y bienes), capacidad de organización y capital social son a menudo bastante notables (Gardner \& Grillo, 2002: 184).

La defunción de un miembro de la comunidad senegalesa genera también la activación de redes de solidaridad comunitaria que permiten hacer frente al elevado coste de una repatriación (entorno a los $8.000 €$ ). Esta adquiere básicamente la forma de cajas de solidaridad

5 Esta investigación se concretó en un proyecto financiado por el Inventario del Patrimonio Etnológico de Cataluña (IPEC), coordinado por Jordi Moreras y que lleva por título Espacios de muerte y diversidad religiosa. La presencia del islam en los cementerios y tanatorios catalanes que finalizó en noviembre de 2010. Los resultados de esta investigación se han publicado en: (Moreras \& Solé Arraràs, 2014). 
comunitaria en las que los miembros pagan una cuota y de colectas espontáneas. Cualquier persona es bienvenida a participar en la recogida de fondos para el traslado de un difunto: parientes, conocidos, vecinos - senegaleses o no- y miembros de la diáspora senegalesa residentes en otros puntos de Catalunya, de España e incluso en otros países europeos. De hecho, no es necesario que las personas que aportan dinero conozcan al difunto sino que, a menudo, se colabora para personas desconocidas. A pesar de no ser su función principal, si el difunto perteneció a una dahira es habitual que sus miembros decidan aportar fondos. Esta recogida de dinero toma pues una dimensión colectiva o comunitaria. Participar en una colecta es una forma de manifestarse como miembro de un colectivo, de mostrar el propio estatus dentro del grupo, así como de considerar miembro de este a la persona enferma o difunta. Por otro lado, estas recogidas de dinero suponen una forma de solidarizarse con los demás, pero también de garantizar que se recibirá la misma ayuda en caso de necesidad.

Se trata de una movilización que, desde mi punto de vista, ha de considerase como parte integrante del ritual funerario. Un rito que genera controversia desde el punto de vista doctrinal islámico pero que, aun así, adquiere una importante capacidad de estructuración social (el debate sobre la repatriación se basa en si debe prevalecer el principio de enterrar al difunto de forma rápida y sencilla en el lugar donde falleció o el hacerlo en el suelo y de cara a la alquibla, algo que no siempre es posible en Europa). ${ }^{6}$ De hecho, son muchos los trabajos sobre los migrantes senegaleses que insisten en la importancia de estas prácticas de solidaridad y cohesión comunitaria. ${ }^{7}$

Cataluña fue, pues, también el escenario para estudiar estas prácticas de solidaridad comunitaria. Éstas se vinculan, como se ha dicho, a distintos tipos de asociaciones de alcance tanto plurinacional, como nacional o local. Otros son los agrupamientos ligados a las vías sufíes (tariqa, sing.; turuq, plural), particularmente la Muridiyya y la Tijaniyya, mayoritarias en Senegal y presentes en Cataluña. Este hecho, junto con las circunstancias del trabajo de campo en Senegal, me llevó a decidir, como se ha explicado anteriormente, que debía centrar la búsqueda en un colectivo limitado desde el punto de vista étnico / lingüístico y por afiliación a una tariqa (personas procedentes de la región de Kolda, de etnia fulbe y seguidores de la tariqa Tijaniyya). Sin embargo, dado que el colectivo implicado en la repatriación de un cadáver suele ir más allá de estos límites, se han entrevistado en Cataluña también personas originarias de otras áreas de Senegal, algunos gambianos y también fulbe seguidores de otras turuq como la Muridiyya.

La convicción de que muchos de los elementos en juego a la hora de optar por una repatriación se gestaban en Kolda y no en Cataluña me llevó, como se ha dicho, a realizar parte del trabajo de campo en esa región. El trabajo en Kolda permitió estudiar el reclamo por parte de las familias y colectivos en origen para que los cuerpos sean trasladados a su lugar de origen.

En el caso de mi tesis doctoral, o en el que describe Katy Gardner (2002) sobre los bengalíes instalados en Londres, la justificación más habitualmente esgrimida para la repatriación es la necesidad de los familiares en origen de ver al difunto para certificar de forma fehaciente su identidad y confirmar la muerte de su pariente. Una interpretación similar ofrecen Clara Saraiva y José Mapril (2012) en un artículo sobre los guineanos y bengalíes en Portugal. En palabras de Françoise Lestage (2008), las familias necesitan "reapropiarse" al difunto. El regreso de los difuntos es además una forma socialmente reconocida de poner fin al estado transitorio que supone la migración facilitando la realización del ritual funerario reinscribiendo al difunto de nuevo en el entorno familiar y social.

Los funerales en la región de Kolda, y en Senegal en general, son grandes acontecimientos en los que se gastan importantes cantidades de dinero y esfuerzos, especialmente para

6 Para un desarrollo de esta argumentación ver: Solé Arraràs (2014)

7 Ver, por ejemplo: Crespo (2006), Riccio (2008), Schmidt di Friedberg, (1994) 
alojar a los asistentes que acuden masivamente. El intercambio de dones (sadaka) es una forma de mantenimiento de las relaciones familiares muy importante para los fulbe. Especialmente aquellos que viven alejados unos de otros. Y uno de los momentos donde este intercambio es más importante es en los ritos funerarios. Entre otros dones, los miembros de la familia doliente sacrifican vacas y bueyes (de gran importancia simbólica para los fulbe) para ofrecerlos como alimento, escenificando y construyendo alianzas familiares. Además, ofrecen a los asistentes nueces de cola (goro) y dulces, tradicionalmente una preparación llamada cobbal (a base de arroz o mijo con azúcar) o galletas. Los asistentes, a su vez, entregan presentes a los dolientes, sobre todo dinero pero también animales, aceite, cereales, etc. Por otro lado, el don más importante que hacen los emigrados a sus parientes es, pues, trasladar el cuerpo para que este pueda ser el centro de la ceremonia. Así, el traslado del cadáver y la realización del ritual funerario, permite a los parientes en el país de origen adquirir un cierto capital simbólico o prestigio exhibiendo los éxitos de su pariente emigrado o en todo caso, no perderlo sufriendo la vergüenza (kersa) de no cumplir con sus obligaciones hacia el difunto y los familiares. Asimismo, permiten también adquirir este honor o evitar esta vergüenza también a los parientes y la comunidad migrada frente a aquellos que han permanecido en Kolda.

Como dice Rubah Salih (2002), en un artículo sobre los rituales que realizan en su país de origen las familias marroquíes emigradas a Italia, los rituales transnacionales son empleados para distribuir recursos simbólicos y económicos entre el país de residencia y el de origen, ambos cruciales en la "economía cultural y política de los migrantes" (Salih, 2002: 222). Permiten lograr reconocimiento a las familias migrantes. Salih afirma que estas prácticas transnacionales son una forma de optimizar escasos recursos para obtener capital simbólico o estatus invirtiéndolos en Marruecos y no en Europa (por ejemplo, la compra de una casa que es más asequible en el país de origen). Entre estas prácticas, Salih destaca también la importancia del ritual como un escenario en el que los emigrados formulan y negocian sus identidades en relación a aquellos que han permanecido en el país de origen. A través de la práctica de un ritual asociado a la "tradición", refuerzan su pertenencia al país de origen al tiempo que, paradójicamente, les permite exhibir un nuevo estatus de riqueza y "modernidad" adquiridas en Europa (ibíd.).

Los rituales funerarios también forman parte de las muchas prácticas de los senegaleses cuyo sentido es conseguir capital simbólico, estatus o prestigio, en Senegal, no en Europa. Unos marcadores de estatus social que tienen que ver con la genealogía, la fama, la piedad religiosa, la generosidad y, cada vez más, la riqueza material (Kane, 2011: 9). Un hecho que, sin duda, tiene que ver con el diferencial económico así como con las dificultades económicas y legales para los desplazamientos físicos entre ambos países. La emigración se entiende en el Fuladú como una situación provisional. El retorno, siempre y cuando se haga habiendo acumulado capital económico y social es, pues, el final más buscado de la aventura migratoria ya sea en vida o tras la muerte.

La fastuosidad de los ritos funerarios, sin embargo, genera también controversias doctrinales puesto que para muchos expertos religiosos sus dispendios son contarios a las enseñanzas islámicas. Éstas defienden la austeridad y sencillez en los funerales y la adopción de una actitud de resignación ante la voluntad divina.

Sin duda, la dimensión islámica de estos rituales es importante. El islam aporta a estos ritos funerarios elementos claves que lo configuran o le dan forma (cómo es tratado el cuerpo, dónde se entierra y de qué manera, etc.), así como una vinculación con elementos dotados de sacralidad y claves en la construcción de una identidad compartida. Como se ha dicho, sin embargo, la forma que adoptan los rituales en la práctica no es la mera traducción en hechos de la norma que emana de los textos doctrinales islámicos. Si en ocasiones se ha entendido esta práctica como una desviación de formas ideales (López Bargados, 2010) hay que entender, por el contrario, que el ritual siempre se produce, se reproduce y se transfor- 
ma en un contexto concreto y es así como hay que observarlo. Entender esto, sin embargo, no quiere decir que este ritual sea menos islámico, por muy doctrinalmente controvertido que sea, lo es en la medida que sus practicantes le consideran. Quiere decir simplemente, que no vamos a encontrar las causas de la repatriación únicamente en la doctrina islámica. Analizar estos rituales desde el punto de vista de su práctica (Bell, 1997; Bourdieu, 2007) nos permite ver cómo gran parte de su eficacia puede radicar en elementos del ritual que no derivan directamente de la doctrina islámica o que son doctrinalmente controvertidos como la repatriación o el intercambio de dones.

La elección del lugar de sepultura en un contexto de migración es una forma de vincularse y de ser vinculado a un grupo de referencia y con un espacio de referencia. Por un lado, un grupo de referencia constituido por la comunidad inmigrante que se moviliza y activa para organizar la repatriación. Por otro, un grupo y un espacio de referencia que se encuentra en el país de origen. Así pues, esta vinculación a un grupo de referencia no es siempre una decisión individual de expresión identitaria; no sólo del individuo al grupo, sino también del grupo al individuo. Usando el concepto de Lestage (2008) de "reapropiación", el traslado del cuerpo difunto al lugar de origen permite que la reapropiación se produzca allí (en Kolda), entre un lugar y otro, y también aquí (en Catalunya). La asunción colectiva de la repatriación de un cadáver es, como se ha dicho, al mismo tiempo un elemento de construcción comunitaria para los colectivos migrantes que debe ser entendido en sí mismo como una parte integrante de un ritual funerario transnacional en transformación.

La práctica sistemática de la repatriación de los cuerpos y el traslado de una parte de la ritualidad funeraria al país de origen, pues, tiene que ver con cómo las comunidades migradas se piensan y se representan a sí mismas. Nos habla, al menos de momento, de comunidades que se construyen sobre la idea de provisionalidad, con el retorno exitoso como el horizonte ideal que debe culminar el proyecto migratorio.

Que la repatriación se mantenga como tendencia principal es, pues, resultado de la asunción de la responsabilidad comunitaria para mantener vivos los vínculos con el origen. Para la comunidad migrada, que adquiere una responsabilidad grupal ante la muerte o la enfermedad grave de uno de sus miembros, recaudar el dinero necesario y trasladar el difunto es responder a lo que se entiende como una "buena muerte".

\section{Seguir a las personas o seguir a las cosas}

En este contexto, donde la necesidad de una etnografía multisituada era evidentemente necesaria para poder tener en cuenta los diversos contextos de este ritual, el planteamiento era como diseñar concretamente la investigación ¿Cómo seleccionar los escenarios concretos o los campos múltiples y móviles en los cuales investigar? ¿Cómo trazar sus límites? Como se ha dicho, baso mi reflexión en dos de las formas o técnicas de la etnografía multisituada de las que habla George E. Marcus (1998): follow the people ("seguir las personas") y follow the thing ("seguir a las cosas").

"Seguir a las personas" es la forma quizás más evidente y más habitual de hacer etnografía multisituada sobre grupos migrantes. Esta implica generalmente centrar la búsqueda en un grupo bien delimitado que constituye una "comunidad transnacional" o "comunidad diaspórica" o "una diáspora". Como señala Floya Anthias (1998), sin embargo, el concepto de diáspora sufre de algunas carencias importantes, especialmente cuando se aplica, como lo hace Cohen (2008), de una forma sustantiva, como una categoría descriptiva de ciertos grupos que pueden ser tipificados como "diásporas" o "comunidades transnacionales". Según Anthias, el concepto de "diáspora" falla en su propósito de cuestionar los esencialismos vinculados a conceptos como "raza" o "etnia", así como a la hora de reconocer las diferencias internas en el seno de estos grupos en materia, entre otros, de clase y género.

Como explica Vered Amit (2001), la "comunidad" ha sido tradicionalmente el escenario 
privilegiado de la etnografía. Según Amit, los antropólogos que han optado por trabajar en contextos transnacionales han seguido tratando de buscar grupos con límites claros a pesar de su dispersión geográfica. Grupos auto-conscientes de constituir una comunidad capaz de adaptarse a la movilidad. Ahora bien, en mi caso y creo que en muchos otros, partir de esta comunidad bien delimitada no era nada fácil pues me encontraba con que las personas que participaban en estos rituales en Cataluña lo hacían en base a identidades múltiples, situacionales y configuraciones identitarias de límites borrosos y cambiantes: musulmán, fulbe, senegalés, tijani, africano, etc.

En este sentido, resultó más apropiada la segunda técnica de Marcus, "seguir una cosa", es decir, construir la etnografía trazando la circulación a través de diferentes contextos de un objeto de estudio manifiestamente material. En este caso, a los cuerpos difuntos. El cuerpo difunto no es exactamente una cosa y su ambigüedad simbólica como persona y/o cosa ha sido un elemento de reflexión de la antropología de la muerte. Sin embargo, tratarlo como un objeto nos sirve a nivel metodológico para construir una etnografía "siguiendo la cosa". Inspirándose en Appadurai (Appadurai, 1986) cuando habló de la "vida social de las cosas", Adriano Favole (Favole, 2003) nos habló de la "vida social de los cadáveres". Se trata, en este caso, de seguir los espacios por los que circulan y las relaciones que se establecen alrededor de estos cadáveres.

Mi investigación, pues, se construyó fundamentalmente siguiendo los cadáveres. Siguiendo cadáveres concretos, en la medida en que fue posible en el seguimiento de casos. Se hizo también -si se me permite seguir una metáfora tan poco respetuosa de tratar a los cuerpos como mercancías- haciendo etnografía siguiendo los escenarios de su "producción", tratamiento y manipulación, traslado, hasta los espacios de sus posibles destinos finales. Desde los momentos previos a la muerte de una persona busqué escenarios donde se "producen" difuntos básicamente en hospitales y unidades de cuidados paliativos. Los escenarios de su tratamiento y manipulación, ya sea ritual o sanitaria son desde los tanatorios donde se realiza el baño, hasta mezquitas u otros espacios donde se realiza la plegaria. El siguiente escenario sobre el que trabajar fueron los espacios del traslado que incluyen aviones, carreteras y aduanas. Finalmente los espacios de sus posibles destinos finales son los cementerios catalanes (islámicos o no) y los de sus localidades de origen donde se realizan parte de los funerales y son enterrados los repatriados.

Buscar y hacer etnografía en los espacios por los que circulan los cuerpos y las relaciones sociales y prácticas que se establecen alrededor y mediante estos me permitió reflexionar cómo el ritual funerario transnacional es, en sí mismo, una forma de construir esta "comunidad transnacional". Me permitió ver como alrededor de estos cuerpos, sobre todo a través de la participación en las colectas para financiar la repatriación se van construyendo distintas configuraciones identitatrias articuladas básicamente entono a la pertinencia religiosa y el vínculo con el origen.

\section{Conclusión}

La construcción de rituales que se producen a la vez en el país de instalación y en el de origen nos habla de la generación de identidades de carácter transnacional, por lo que los traslados de cadáveres producen nuevos lugares, nuevos escenarios de pertenencia. A su vez, producen y mantienen vínculos entre las comunidades emigradas contribuyendo a su definición y reestructuración. A través de este ritual el colectivo se representa a sí mismo como una única comunidad, ligada y fundida con otra que se representa como existiendo en el país de origen.

Por otro lado, la identidad religiosa es, también, uno de los elementos vertebradores de una identidad grupal o comunitaria que el ritual activa. Las organizaciones vinculadas a la tariqa Tijaniyya, mayoritaria en Kolda, tienen su papel en la movilización comunitaria para 
la repatriación. Además, la identidad musulmana es uno de los denominadores comunes que unen a las personas procedentes de Kolda también común con muchos otros senegaleses.

Sin embargo, el colectivo que se moviliza para la repatriación no es una comunidad bien delimitada por la identidad ni "confrérica", ni religiosa. Por el contrario, hablamos de una red informe que se teje y desteje para cada caso personal y puede trascender estos límites así como los étnicos, nacionales, etc. La movilización para el traslado de un cadáver contribuye a crear un sentido auto-percibido de comunidad, una comunidad que se construye en la práctica del ritual y, en parte, gracias a él, que existe por lo menos cuando se moviliza. Una "comunidad transnacional" que no puede ser pues el punto de partida para diseñar nuestra etnografía multisituada sino al contrario que solo percibimos gracias a esta.

Así, desde mi punto de vista, el estudio de los rituales transnacionales requiere la adopción de una etnografía centrada en la práctica ritual más que una que busque perseguir allende las fronteras a miembros de un mismo grupo cultural o religioso. Como argumenta Bruno Riccio al hablar de las prácticas trasnacionales de los senegaleses mourides en Italia, el transnacionalismo es un establecimiento de redes constante en el seno de estos espacios transnacionales, pero no son redes establecidas dentro de comunidades cerradas. Lejos de ser un sistema homogéneo abarca una amplia variedad de prácticas diferentes y que varían según la situación. Vemos, por ejemplo, como en algunos casos, se tratan de superar las diferencias religiosas y étnicas entre compatriotas. En otros, estas emergen como significativas (Riccio, 2004: 596). Seguir las dimensiones físicas y materiales de estas celebraciones nos permite ver cómo se construyen los "nosotros" y "otros" a los que todo ritual interpela (Baumann, 1992). Como dicen Gardner y Grillo (2002), los rituales transnacionales en constante transformación permiten afirmar la pertenencia, o el reclamo, a veces contestado, de seguir perteneciendo a la comunidad de origen.

Determinados objetos de estudio, y yo me centro en aquellos que tienen que ver con colectivos migrantes, requieren de forma casi ineludible ser estudiados a través de etnografías multisituadas. Los migrantes son al mismo tiempo emigrantes e inmigrantes y, como defiende la perspectiva transnacional, mantienen constantes relaciones con sus países de origen. Ignorar alguno de estos escenarios puede implicar dejar de lado importantes dimensiones de nuestro objeto de estudio. En mi caso, por ejemplo, el reclamo por parte de las familias en origen, la importancia del ritual en kolda, etc.

Sin embargo, no siempre resulta sencillo trazar el marco concreto de una etnografía multisituada. La delimitación del campo de estudio se vuelve compleja y requiere de técnicas como las que propone Marcus (op cit.) que nos permiten establecer el puente entre los múltiples escenarios de la etnografía de forma coherente. Igualmente requiere urdir una narración etnográfica que permita ver un único objeto de estudio en múltiples escenarios.

\section{Bibliografía}

Anthias, F. (1998). Evaluating "Diaspora": Beyond Ethnicity? Sociology, 32(3): 557-580. http://doi. org/10.1017/S0038038598000091

Appadurai, A. (1986). The Social Life Of Things. (A. Appadurai, Ed.). Cambridge: Cambridge University Press.

Baumann, G. (1992). Ritual implicates "Others": rereading Durkheim in a plural society. In D. De Coppet (Ed.), Understanding Rituals. London: Routledge.

Bell, C. (1997). Ritual perspectives and dimensions. Oxford [etc.]: Oxford University Press.

Bourdieu: (2007). El sentido práctico. Madrid: Siglo XXI.

Cohen, R. (2008). Global diasporas: an introduction. New York: Routledge.

Crespo, R. (2006). Participación y asociacionismo senegalés de la visibilidad a la conexión transcontinental. In M. Jabardo (Ed.), Senegaleses en España. Conexiones entre origen y destino. Madrid: Ministerio de Trabajo y Asuntos Sociales.

Favole, A. (2003). Resti di umanità. Vita sociale del corpo dopo la morte. Roma: Laterza. 
Gardner, K. (2002). Death of a migrant: transnational death ritual and gender among British Sylhetis. Global Networks, 2(3): 191-205.

Gardner, K., \& Grillo, R. (2002). Transnational households and ritual: an overview. Global Networks, 2(3): 179-190.

Glick Schiller, N., Basch, L., \& Blanc Szanton, C. (Eds.) (1992). Towards a transnational perspective on migration. Race, class, Ethnicity, and Nationalism Reconsidered. New York: New York Academy of Sciences.

Kane, O. O. (2011). The Homeland Is the Arena: Religion, Transnationalism, and the Integration of Senegalese Immigrants in America. Oxford [etc.]: Oxford University Press.

Lestage, F. (2008). Le dernier voyage des migrants mexicains. Ethnographie du retour des défunts. CMHLB Caravelle, 91: 1-13.

López Bargados, A. (2010). Los (d)efectos del texto: controversias en torno a las prácticas rituales de los musulmanes europeos. Etnografica, 14(2): 213-242. http://doi.org/10.4000/etnografica. 271

Marcus, G. E. (1998). Ethnography through Thick and Thin. Princeton: Princeton University Press.

Moreras, J., \& Solé Arraràs, A. (2014). Espais de mort i diversitat religiosa. La presència de l'islam als cementiris i tanatoris catalans. Barcelona: Generalitat de Catalunya. Departament de cultura. Recuperado de: http://www20.gencat.cat/docs/CulturaDepartament/CULTURA_POPULAR_nova_web/07_Publicacions_nou/ESTATICS I DOCUMENTS/SD_Espais_de_mort.pdf

Naranjo, J. (2009). Los invisibles de Kolda. Barcelona: Península.

Popovic, A., \& Veinstein, G. (Eds.). (1997). Las Sendas de Allah : las cofradías musulmanas desde sus orígenes hasta la actualidad. Barcelona: Bellaterra.

Riccio, B. (2004). Transnational Mouridism and the Afro-Muslim Critique of Italy. Journal of Ethnic and Migration Studies, 30(5): 929-944.

Riccio, B. (2008). From "ethnic group" to "transnational community"? Senegalese migrants' ambivalent experiences and multiple trajectories. Journal of Ethnic and Migration Studies, 27(4): 583-599.

Salih, R. (2002). Reformulating Tradition and Modernity: Moroccan Migrant Women and the Transnational Division of Ritual Space. Global Networks, 2(3). Recuperado de: http://eprints. soas.ac.uk/12388/

Saraiva, C., \& Mapril, J. (2012). Le lieu de la "bonne mort" pour les migrants guinéens et bangladais au Portugal. Revue Européenne Des Migrations Internationales, 28(3): 51-70.

Schmidt di Friedberg, O. (1994). Islam, solidarietà e lavoro: i muridi senegalesi in Italia. Torino: Edizioni della Fondazione Giovanni Agnelli.

Solé Arraràs, A. (2014). Ritos funerarios islámicos trasnacionales entre Catalunya y Kolda (Senegal). La construcción de la transnacionalidad desde la práctica religiosa y ritual . Revista de Estudios Internacionales Mediterráneos, 16: 1-16.

Solé Arraràs, A. (2015). Rituals funeraris islàmics transnacionals. La repatriació de difunts entre Catalunya i Kolda (Senegal). Universitat de Barcelona.

Sow, P., \& Mercader, N. (2005). Migracions senegaleses a Catalunya. Relacions amb les comunitats d'origen. Barcelona: Fons Català de Cooperació al Desenvolupament.

\section{3}

